\title{
Hydatid disease of the spine
}

In humans, hydatid disease of the spine is a rare form of parasitic infection, causing focal neurological signs, commonly observed in sheep-raising areas of the world, and it affects the vertebral column in $0.2-1 \%$ of all patients of which spine is involved in approximately $45 \%$ of cases $^{[1-4]}$ even in rural areas where echinococcosis is endemic and ${ }^{[5,6]}$ dead end of parasite of hydatid in its life cycle is human. ${ }^{[1-6]}$ Due to the rarity of its presentation, unless the clinician includes spinal hydatid disease as part of the differential list for paralysis and considers performing neuroimaging, this potentially curable disease will be missed. ${ }^{[7-10]}$ Vertebral hydatidosis commonly involves the thoracic vertebrae and the cervical, lumbar vertebrae and sacrum are rare sites to be involved. ${ }^{[11-15]}$ However, it remains controversial as to which region is more commonly involved. ${ }^{[16]}$

Spinal hydatid disease manifests itself through symptoms and signs related to compression of the cysts on other structures; no specific pathognomonic symptoms or signs exist. ${ }^{[17,18]}$ Generally, the disease presents with radiculopathy, myelopathy and/or local pain owing to bony destructive lesions, pathological fracture and consequent cord compression..$^{[1,19]}$ In some patients, the spinal hydatid cysts can grow to enormous size and clinically remain asymptomatic for years. ${ }^{[1,19,20]}$ Hydatid cysts of the sacrum are no exception and are characterized by chronicity without any clinical manifestation and usually misdiagnosed in the early stage, resulting in significant loss of bone and destruction of surrounding tissue. ${ }^{[21]} \mathrm{A}$ missed diagnosis of hydatid cyst could be devastating and hydatid cyst should be kept as a differential diagnosis when encountered with a cystic lesion of sacrum. ${ }^{[14]}$

Radiologically, computed tomography (CT) scanning and ultrasonography is a useful combination both for achieving a correct diagnosis and for planning of appropriate treatment. ${ }^{[2,3,22]}$ The differential diagnosis of cystic lesion of sacrum includes developmental cysts [epidermoid, dermoid, teratoma, neurenteric and retrorectal cystic hamartoma (tail gut cyst)], anterior sacral meningocele, necrotic sacral chordoma, schwannoma, arachnoid cyst, Tarlov's cyst and aneurysmal bone cyst. ${ }^{[11,23]}$ Magnetic resonance imaging (MRI) is the preferred imaging modality in the diagnosis of hydatid cysts ${ }^{[17]}$ and recent use of diffusion-weighted
MRI has been shown to help differentiate complicated infected hydatidosis from abscesses, epidermoid cysts from arachnoid cysts, and benign from malignant vertebral compression fractures. ${ }^{[4,24]}$ Diffusion-weighted MRI can also help differentiate between infections requiring immediate surgery and those that can be treated medically with antihelmintic treatment. ${ }^{[24]}$ Interestingly, fine needle aspiration cytology enabling the diagnosis of hydatid cyst without procedure-related complication is reported in literature.

Successful treatment of spinal hydatid disease necessitates careful neuroradiological evaluation, aggressive surgical intervention and this plus adjuvant chemotherapy in some cases. ${ }^{[2,25,26]}$ The initial treatment of choice is surgical excision for neural decompression, and establishing diagnosis and en masse excision of the spinal lesion depends largely depends on the location and the extent of the lesion. ${ }^{[12]}$ The type of surgical procedures, extent of resection and decision whether to perform spinal stabilization or not to fuse depends on the site and extent of the disease and bone involvement and destruction causing spinal instability. $[18,27,28]$ Albendazole is the preferred antihelminthic agent in the treatment of hydatid disease; presurgical use of albendazole in echinococcus infestations reduces risk of recurrence and/or facilitates surgery by reducing intracystic pressure, ${ }^{[16,26]}$ but the duration of treatment is controversial. ${ }^{[26]}$ Though uncommon, the suggested treatment for hydatid cyst can be aspiration and reperfusion of cyst by albendazole..$^{[1,11,12]}$

Strict follow-up is critical in the management of these patients ${ }^{[2,3,29]}$ and regular MRI scans should be done during the postoperative period in order to ensure that any recurrence is detected early, ${ }^{[29]}$ as despite optimal and medical therapy, recurrence and thus reoperations are generally needed. ${ }^{[30,31]}$ Overall recurrence rate of $30-40 \%{ }^{[32]}$ and a $50 \%$ recurrence rate after posterior decompression alone are reported. ${ }^{[32]}$

It has been recommended that spinal hydatidosis should be considered in the differential diagnosis of any patient who has lived or traveled within endemic areas and who presents with spine lesions and cord compression. ${ }^{[6]}$ It has been well said that "although total removal of the cysts without rupture should be the surgical goal in all 
cases, the best treatment remains an active nationwide prevention of the disease". ${ }^{[33]}$

\section{Arvind Bhake, Amit Agrawal ${ }^{1}$}

Departments of Pathology, Datta Meghe Institute of Medical Sciences, Sawangi (Meghe), Wardha, Maharashtra, ${ }^{1}$ Department of Neurosurgery, MM Institute of Medical Sciences \& Research, Maharishi Markandeshwar University, Mullana- Ambala, 133-207, Haryana, India

Address for correspondence Dr. Amit Agrawal, Professor and Head, Department of Neurosurgery, MM Institute of Medical Sciences \& Research, Maharishi Markandeshwar University, Mullana- Ambala, 133-207, Haryana, India Email-dramitagrawal@gmail.com,dramit_in@yahoo.com

DOI: $10.4103 / 0976-3147.71715$

\section{References}

1. Abbassioun K, Amirjamshidi A. Diagnosis and management of hydatid cyst of the central nervous system: Part 2: Hydatid cysts of the skull, orbit, and spine. Neurosurg Q 2001;11:10-6.

2. Turgut M. Hydatid disease of the spine: A survey study from Turkey. Infection 1997;25:221-6.

3. Turgut AT, Altin L, Topçu S, Kiliçoğlu B, Aliinok T, Kaptanoğlu E, et al. Unusual imaging characteristics of complicated hydatid disease. Eur J Radiol 2007;63:84-93.

4. Secer HI, Anik I, Celik E, Daneyemez MK, Gonul E. Spinal hydatid cyst mimicking arachnoid cyst on magnetic resonance imaging. J Spinal Cord Med 2008;31:106-8.

5. Basak M, Ozel A, Yildirim O, Erturk M. Relapsing hydatid disease involving the vertebral body and paravertebral soft tissues. Acta Radiol 2002;43:192-3.

6. Schnepper GD, Johnson WD. Recurrent spinal hydatidosis in North America: Case report and review of the literature. Neurosurg Focus 2004;17:E8.

7. Ndondo AP, Fieggen G, Wilmshurst JM. Hydatid disease of the spine in South African children. J Child Neurol 2003;18:343-6.

8. Yilmaz N, Ozgocmen S, Kocakoc E, Kiris A. Primary hydatid disease of sacrum affecting the sacroiliac joint: A case report. Spine (Phila Pa 1976) 2004;29:E88-90.

9. Ergin A, Toker T, Yanarates O, Kurt E, Guzeldemir ME. A typical low-back pain caused by an atypical etiology. Reg Anesth Pain Med 2007;32:89-92.

10. Layadi F, Boubrik M, Ait El Qadi A, Ait Benali S. Primary sacral epidural hydatid cyst: A case report. J Radiol 2005;86:1040-2.

11. Song X, Liu D, Wen H. Diagnostic pitfalls of spinal echinococcosis. J
Spinal Disord Tech 2007;20:180-5.

12. Işlekel S, Erş̧ahin Y, Zileli M, Oktar N, Oner K, Ovül I, et al. Spinal hydatid disease. Spinal Cord 1998;36:166-70.

13. Fiennes AG, Thomas DG. Combined medical and surgical treatment of spinal hydatid disease: A case report. J Neurol Neurosurg Psychiatry 1982;45:927-30.

14. Patel D, Shukla D. Back bugged: A case of sacral hydatid cyst. J Neurosci Rural Pract 2010;1:43-5.

15. Shukla S, Trivedi A, Singh K, Sharma V. Primary lumbosacral intradural hydatid cyst in a child. J Neurosci Rural Pract 2010;1:109-111.

16. Sharma NK, Chitkara N, Bakshi N, Gupta P. Primary spinal extradural hydatid cyst. Neurol India 2003;51:89-90.

17. Berk C, Ciftci E, Erdogan A. MRI in primary intraspinal extradural hydatid disease: Case report. Neuroradiology 1998;40:390-2.

18. Pamir MN, Akalan N, Ozgen T, Erbengi A. Spinal hydatid cysts. Surg Neurol 1984;21:53-7.

19. Joshi N, Hernandez-Martinez A, Seijas-Vazquez R. Primary sacral hydatid cyst: A case report. Acta Orthop Belg 2007;73:674-7.

20. Govender TS, Aslam M, Parbhoo A, Corr P. Hydatid disease of the spine: A long-term followup after surgical treatment. Clin Orthop Relat Res 2000;378:143-7.

21. Dogra PN, Nabi G. Sacral hydatid cysts: An uncommon cause of neurogenic bladder. Urol Int 2000;65:214-5.

22. Turgut AT, Turgut M. Intradural extramedullary primary hydatid cyst of the spine in a child: A very rare presentation. Eur Spine J 2009;18:1234-5

23. Song XH, Ding LW, Wen H. Bone hydatid disease. Postgrad Med J 2007;83:536-42.

24. Doganay S, Kantarci M. Role of conventional and diffusion-weighted magnetic resonance imaging of spinal treatment protocol for hydatid disease. J Spinal Cord Med 2009;32:574-7.

25. Ozdemir HM, Ogun TC, Tasbas B. A lasting solution is hard to achieve in primary hydatid disease of the spine: Long-term results and an overview. Spine (Phila Pa 1976) 2004;29:932-7.

26. Garcia-Vicuna R, Carvajal I, Ortiz-Garcia A, Lopez-Robledillo JC, Laffon A, Sabando P. Primary solitary Echinococcosis in cervical spine: Postsurgical successful outcome after long-term albendazole treatment. Spine (Phila Pa 1976) 2000;25:520-3.

27. Khazim RM. Spinal hydatid disease. South Med J 2006;99:114.

28. Pamir MN, Ozduman K, Elmaci I. Spinal hydatid disease. Spinal Cord 2002;40:153-60

29. Ouma JR. Echinococcosis-a rare spinal disorder. S Afr Med J 2006;96: 680, 682.

30. Fares Y, Khazim R, El Zaatari MM, Haddad GF, Barnes PR. Spinal hydatid disease and its neurological complications. Scand J Infect Dis 2003;35:394-6.

31. Chaudhary K, Bapat M, Badve S. Paraplegia due to recurrent multiple hydatid cyst of the spine: A case report. Indian J Orthop 2008;42:222-4.

32. Turtas S, Viale ES, Pau A. Long-term results of surgery for hydatic disease of the spine. Surg Neurol 1980;13:468-70.

33. Gunecs M, Akdemir H, Tugcu B, Gunaldi O, Gumucs E, Akpinar A Multiple intradural spinal hydatid disease: A case report and review of literature. Spine (Phila Pa 1976) 2009;34:E346-50.

Source of Support: Nil, Conflict of Interest: None declared. 